\title{
The addition of albumin improves Schwann cells viability in nerve cryopreservation
}

\author{
Sara Alicia González Porto ${ }^{1}$, Nieves Domenech ${ }^{2,3}$, Alba González Rodríguez ${ }^{4}$, Edgar \\ Mauricio Avellaneda Oviedo ${ }^{4}$, Francisco J Blanco ${ }^{5}$, María C Arufe Gonda 6 , Ángel \\ Álvarez Jorge ${ }^{4}$, Jacinto Sánchez Ibañez ${ }^{7}$, Esther Rendal Vázquez ${ }^{7}$
}

${ }^{1}$ Servicio de Cirugía Plástica, Complexo Hospitalario Universitario de A Coruña (CHUAC), Servicio Galego de Saúde (SERGAS), Hospital Universitario de A Coruña, Xubias de Arriba 84, 15006, A Coruña, Spain. aras_678@hotmail.com.

${ }^{2}$ Biobanco A Coruña- Instituto de Investigación Biomédica de A Coruña (INIBIC), A Coruña, Spain.

${ }^{3}$ Centro de Investigación Biomédica en Red de Enfermedades Cardiovasculares (CIBERCV), Madrid, Spain.

${ }^{4}$ Servicio de Cirugía Plástica, Complexo Hospitalario Universitario de A Coruña (CHUAC), Servicio Galego de Saúde (SERGAS), Hospital Universitario de A Coruña, Xubias de Arriba 84, 15006, A Coruña, Spain.

5 Grupo de Investigación de Proteómica-PBR2-ProteoRed/ISCIII-Servicio de Reumatología, Instituto de Investigación Biomédica de A Coruña (INIBIC), Complexo Hospitalario Universitario de A Coruña (CHUAC), Servicio Galego de Saúde (SERGAS), Universidade da Coruña (UDC), A Coruña, Spain.

${ }^{6}$ Grupo de Terapia Celular y Medicina Regenerativa (TCMR-CHUAC), CIBER BBN/ISCIII, Instituto de Investigación Biomédica de A Coruña (INIBIC), Complexo Hospitalario Universitario de A Coruña (CHUAC), Servicio Galego de Saúde (SERGAS), Ciencias Biomédicas, Medicina y Fisioterapia, Facultade de Oza, Universidade da Coruña (UDC), A Coruña, Spain.

${ }^{7}$ Unidad de Criobiología, Banco de Tejidos, Complexo Hospitalario Universitario de A Coruña (CHUAC), Servicio Galego de Saúde (SERGAS), A Coruña, Spain.

\begin{abstract}
The purpose of the current study was to establish a valid protocol for nerve cryopreservation, and to evaluate if the addition of albumin supposed any advantage in the procedure. We compared a traditional cryopreservation method that uses dimethyl sulfoxide (DMSO) as cryoprotectant, to an alternative method that uses DMSO and albumin. Six Wistar Lewis rats were used to obtain twelve $20 \mathrm{~mm}$ fragments of sciatic nerve. In the first group, six fragments were cryopreserved in 199 media with $10 \%$ DMSO, with a temperature decreasing rate of $1{ }^{\circ} \mathrm{C}$ per minute. In the second group, six fragments were cryopreserved adding $4 \%$ human albumin. The unfreezing process consisted of sequential washings with saline in the first group, and saline and $20 \%$ albumin in the second group at $37{ }^{\circ} \mathrm{C}$ until the crioprotectant was removed. Structural evaluation was performed through histological analysis and electronic microscopy. The viability was assessed with the calcein-AM (CAM) and 4',6-diamino-2-fenilindol (DAPI) staining. Histological results showed a correct preservation of peripheral nerve architecture and no significant differences were found between the two groups. However, Schwann cells viability showed in the CAM-DAPI staining was significantly superior in the albumin group. The viability of Schwann cells was significantly increased when albumin was added to the nerve cryopreservation protocol. However, no significant structural differences were found between groups. Further studies need to be performed to assess the cryopreserved nerve functionality using this new method.
\end{abstract}

Keywords: Cryopreservation; Dimethyl sulfoxide; Peripheral nerve injuries; Serum albumin. 


\section{Introduction}

The main current indication for the use of cryopreserved nerve allografts is the reconstruction of extensive injuries of the peripheral nerve system (Mackinnon 1989). Nevertheless, the concept of tissue banking is an emerging field, and experimental research is being performed to find the protocols for the cryopreservation of several organs and tissues (Arav et al. 2017; Giwa et al. 2017; Zhang et al. 1998). Tissue allotransplantation has being performed successfully in a clinical setting, and cryopreservation could be used regarding its immunomodulatory properties and allowing tissue preservation for indefinite time (Dubernard and Devauchelle 2008). Tissue banking could allow immediate availability of different tissues for reconstructive purposes.

The cryopreservation is a method for preserving tissues through the use of cold, leading to reduced tissue methabolic needs and to the immediate availability of the graft (Bakhach et al. 2007). The cryopreservation was proved successful in animal and human reproductive cells, arterial and venous vessels, tendon, cartilage, bone, heart valves, corneal tissue or skin (Jung et al. 2016; Li et al. 2017; Kiroshka et al. 2017; Shabani Nashtaei et al. 2017; Esther Rendal Vázquez et al. 2004; Sriuttha et al. 2016; Lisy et al. 2017; Díaz Rodríguez et al. 2017; Routledge and Armitage 2003; Pianigiani et al. 2016). Recently, it was also performed in composite tissue allografts, such as the epigastric flap in a rat model, with reported good outcomes (Cui et al. 2007).

The nerve cryopreservation may lead to a decreased immunogenic response in the hostage, and would permit the storage of nerve tissue in tissue banking, being an immediate alternative in case of extent injury to the peripheral nerve system (Fansa et al. 2000). These immunomodulatory properties of cryopreservation have been associated to a reduction in cell viability. In the case of peripheral nerve, Schwann cells have been pointed out as the main immunogenic material within the nerve allograft. Cryopreservation of peripheral nerve leads to reduced Schwann cell viability, which helps decreasing immunogenic response.

However, Schwann cells play an important role in nerve regeneration. That is the reason why the nerve regeneration through acellular nerve allografts is decreased compared to isografts (Fairbairn et al. 2016). The ideal protocol for nerve cryopreservation would allow preserving the viability of Schwann cells, and achieving immunotolerance or a decrease in host immunogenic response at the same time. In fact, cryopreservation proved to reduce the metabolic activity and the release of pro-inflammatory cytokines from the cryopreserved tissues, leading to a reduced monocyte and $\mathrm{T}$ cell migration (Schneider et al. 2017).

The cryopreservation process is citotoxic because of two different mechanisms: the first one is due to the increase of extracellular osmolarity, the second one is due to the intracellular ice formation. Since there is an increased risk of cell death linked to cryopreservation, and only Schwann cells are sensitive to freezing in the peripheral nerve, the main objective of the process should be keeping the viability of Schwann cells, that would be unachievable in uncontrolled freezing (Arnaud 1992; Lassner et al. 1995). One of the parameters we must evaluate to reduce cell death is the cooling rate, and also the thawing rate, both of which depend on the tissue involved. Regarding nerve tissue, the best cryopreservation protocol to preserve Schwann cells viability and nerve architecture seems to be slow freezing and fast thawing (Zhu et al. 2014a).

In addition, the cryopreservation of solid tissues such as nerve, unlike cell suspensions, could be subjected to other risks, such as fractures of the tissue. The protocol for nerve cryopreservation must ensure the absence of cracks or fractures of the nerve, which could compromise the use of the graft as a channel for nerve regeneration.

Other parameters that would determine the viability of Schwann cells are the ischaemia time, the preservation solution used or the correct storage of the cryopreserved nerve graft (Arnaud 1992).

Another variable that increases cell viability is the addition of cryoprotectant, such as glicerol or dimethyl sulfoxide (DMSO), which decreases the hyperosmolarity lesion, and are also specific for each tissue. Albumin is a serum high weight protein which acts as a stabilizing cell membrane protein, which is widely used in tissue banks for the cryopreservation of cells (hematopoietic progenitor cells) and tissues (heart valves, arteries, corneal tissue) (Delbosc et al. 1984). 
The purpose of the current study was to establish a valid protocol for nerve cryopreservation by evaluating histological features of cryopreserved nerve allografts, and to evaluate if the addition of albumin supposed any advantage in the procedure. We compared a traditional cryopreservation method that uses DMSO as cryoprotectant, to an alternative method that uses DMSO and albumin.

\section{Methods}

Supply of the nerves

The study was approved by the Institutional Review Board (Ethics Committee of Animal Experimentation at the University Hospital of A Coruna) and all animal care complied with the Guide for the Care and Use of Laboratory Animals. Six Wistar Lewis rats were used to obtain twelve $20 \mathrm{~mm}$ fragments of sciatic nerve. The surgical procedure was done under inhalation anaesthesia, and the euthanasia of the animal was performed in the same surgery, using intracardiac injection of potassium chloride, to avoid postoperative suffering.

Preparation of the nerves

Cold ischaemia (time from surgical removal of the nerve to antibiotic incubation) was inferior to $1 \mathrm{~min}$. The nerve fragments were stored in sterile containers with antibiotic solution, at $4{ }^{\circ} \mathrm{C}$ for $20-24 \mathrm{~h}$. The composition of the antibiotic solution was Vancomycin $50 \mathrm{mg} / \mathrm{l}$, Amphotericin $5 \mathrm{mg} / \mathrm{l}$, Amikacin $50 \mathrm{mg} / \mathrm{l}$ and Metronidazole $50 \mathrm{mg} / \mathrm{l}$. After antibiotic incubation, the nerves were washed with saline and a $3 \mathrm{~mm}$ sample was taken for histology analysis.

Experimental groups

In the first group, six fragments were cryopreserved in 199 media with $10 \%$ of DMSO, without using albumin neither in the cryopreservation media nor in the unfreezing process.

In the second group, six fragments were cryopreserved in 199 media with $10 \%$ DMSO and $4 \%$ human albumin, and during the unfreezing process sequential washings with saline and $20 \%$ human albumin were performed.

\section{Cryopreservation and thawing}

The volume of the cryopreservation solution per sample was $5 \mathrm{ml}$. The type of flask used is a $5 \mathrm{ml}$ cryovial.

For the cryoprotectant addition in the DMSO and albumin group, a $5 \mathrm{ml}$ solution containing DMSO (10\%), albumin (4\%) and TC-199 media (86\%) was prepared. The nerve was placed in the cryovial, and the solution was added drop by drop for $2 \mathrm{~min}$. The cryovial was then stirred for $10 \mathrm{~min}$ at $4{ }^{\circ} \mathrm{C}$.

For the cryoprotectant addition in the DMSO group, a $5 \mathrm{ml}$ solution containing DMSO (10\%) and TC199 media (90\%) was prepared. As it was with the DMSO and albumin group, the nerve was placed in the cryovial, and the solution was added drop by drop for $2 \mathrm{~min}$. The cryovial was then stirred for $10 \mathrm{~min}$ at $4{ }^{\circ} \mathrm{C}$.

Cryopreservation was carried out in a biological refrigerator (CM25 Carburos Metalicos SA, Madrid, Spain) with a programed temperature decrease of $1{ }^{\circ} \mathrm{C} / \mathrm{min}$ until a temperature of $-40{ }^{\circ} \mathrm{C}$ was reached, and with cooling rate of $5{ }^{\circ} \mathrm{C} / \mathrm{min}$ thereafter until $-140{ }^{\circ} \mathrm{C}$ was reached. The cooling rate was identical for both groups. The fragments were individually stored in sterile flasks inside tanks of nitrogen in gas phase at $-140{ }^{\circ} \mathrm{C}$ for 3 weeks. 
The thawing process was conducted at room temperature for $5 \mathrm{~min}$, and then using a water bath at $37^{\circ} \mathrm{C}$ for another $5 \mathrm{~min}$.

After that, five to six sequential washings of $5 \mathrm{~min}$ each were performed. For the DMSO and albumin group, three wells were prepared containing $5 \mathrm{ml}$ of $20 \%$ albumin each. The nerve was left $3 \mathrm{~min}$ in each of them sequentially. For the DMSO group, one well was filled with $5 \mathrm{ml}$ from the cryovial and another $5 \mathrm{ml}$ of saline. With a syringe, $5 \mathrm{ml}$ were removed and $5 \mathrm{ml}$ of saline were added, this proscess being repeated 5-6 times.

\section{Histological analysis}

Two $3 \mathrm{~mm}$ sample were taken from the proximal part of each nerve before cryopreservation for histological analysis and electronic microscopy. This control group of fresh samples were taken after antibiotic incubation.

After cryopreservation, thawing, and removing the cryoprotectant, a macroscopical qualitative assessment was performed by the neuropathologist and two samples were taken from the proximal part of each nerve for optical microscopy (hematoxylin and eosin and toluidine blue) and for electronic microscopy. The remaining nerve was used to assess viability through calcein-AM (CAM) and 4',6-diamidino-2phenylindole (DAPI) staining.

\section{Hematoxylin and eosin}

The fixation with $10 \%$ formalin was performed for $24 \mathrm{~h}$, followed by gradient alcohol dehydration. After that, the nerve segment was embedded in paraffin and transverse sections of $4 \mu \mathrm{m}$ width were cut with a microtome. The deparaffinization of the slices was done at $60{ }^{\circ} \mathrm{C}$ in a heater, and with xylene. The slices were later hydrated by immersion in $100^{\circ}$ alcohol, $96^{\circ}$ alcohol and tap water, and stained by Harris hematoxylin for $5 \mathrm{~min}$. After that, they were rinsed in tap water, incubated in eosin staining for $1 \mathrm{~min}$, dehydrated in $96^{\circ}$ alcohol and $100^{\circ}$ alcohol, immersed in xylene and protected with clarity gum. Hematoxylin and eosin staining slices were observed under light microscopy to see the general structure of the nerve.

\section{Toluidine blue}

Nerve fragments were fixed in $2.5 \%$ glutaraldehyde for $12 \mathrm{~h}$ at $4{ }^{\circ} \mathrm{C}$ in $0.1 \mathrm{M}$ cacodylate buffer with $\mathrm{pH}$ 7.4. This is followed by postfixation in $1 \%$ osmium tetroxide, dehydration by immersion in ascending series of acetone, and inclusion in a SPURR low-viscosity epoxy resin. The segments were cut with the ultramicrotome in $1 \mu \mathrm{m}$ slices and died with toluidine blue that were observed under optic microscope.

\section{Electronic microscopy}

Processing of the samples is common to toluidine blue staining, except for the cutting with the ultramicrotome in $60 \mathrm{~nm}$ slices that were observed under transmission electron microscope JEM 1010 (Jeol, Akishima, Japan). Images were taken with a digital camera Mega View III and analyzed by the software analySIS (Soft Imaging System GmbH, Olympus, Shinjuku, Japan).

The electronic microscopy was useful to evaluate the integrity of Schwann cells, myelin sheath and basal lamina. The histology technician was blinded to the method of cryopreservation used. 
Viability assessment

CAM (calcein AM) and DAPI (4',6-diamidino-2-phenylindole) staining

To investigate the viability of the sciatic nerves, live cells were labeled by CAM (calcein-AM) and the nucleus of apoptotic cells was stained with DAPI (4',6-diamidino-2-phenylindole).

CAM consists of an acetomethoxy group joined to calcein. It penetrates the plasmatic membrane and in the viable cell intracellular esterases degrade calcein-AM to calcein, turning all living cells fluorescent green (Grogan et al. 2002; Martinez-Madrid et al. 2004).

DAPI is a blue fluorescent marker which crosses the cellular membrane, enter the cell nucleus and bind to DNA, specially in sequences containing adenine and thymine. Cell membrane permeability is higher in dead cells than in live cells for DAPI, which is consequently used as an apoptosis cell marker (Yang et al. 2017).

The nerve fibers were stained with CAM $(2 \mu \mathrm{mol} / \mathrm{l})$ at $37^{\circ} \mathrm{C}$ for $15 \mathrm{~min}$ in the dark, and also with DAPI $(5 \mu \mathrm{mol} / \mathrm{l})$ at $37^{\circ} \mathrm{C}$ for $30 \mathrm{~min}$ in dark, and washed with phosphate buffer saline to remove the staining solution. The fluorescent intensity was measured under a laser scanning confocal microscope and analyzed with an image system (LAS-AF-Lite 2.6, Leica, Germany) at 200x as described previously (Ma et al. 2012). The assessment of the viability of each nerve was performed by two laboratory technicians, blinded to the method of cryopreservation used for each sample.

Statistical analysis

Cuantitative variables were expressed as the mean \pm SD (Standard Deviation). Mann-Whitney test was applied for assessing Schwann cell viability. SPSS 22.0 software (SPSS, Chicago, IL, US) was used for analysis. A $p<0.05(<5 \%)$ was considered a significant difference.

\section{Results}

\section{Macroscopical examination}

The macroscopical appearance of the cryopreserved nerves from both groups was similar to fresh sciatic nerves (Fig. 1). There was no edema, shrinkage or noticeable alterations of the elasticity. There were no fractures in any of the nerve fragments.

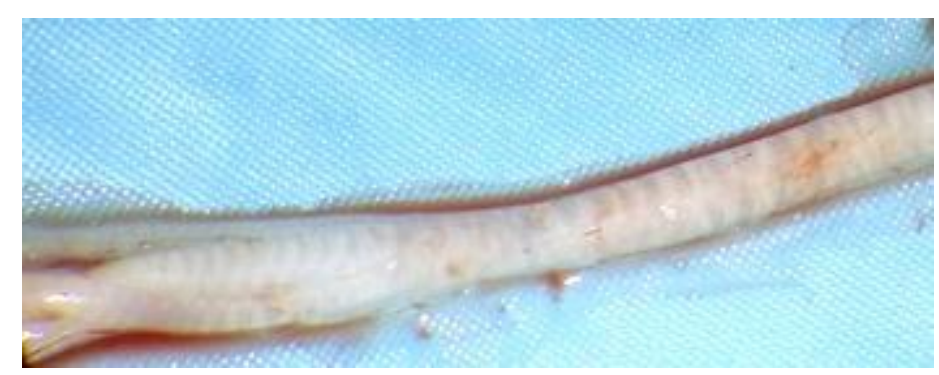

Fig. 1. Macroscopic aspect of the sciatic nerve after cryopreservation with DMSO and albumin. The transverse and oblique bands along the nerve correspond to the bands of Fontana, typically seen in normal nerves 
Hematoxylin and eosin and toluidine blue

Staining the samples with hematoxylin and eosin and toluidine blue did not reveal any obvious differences between the group cryopreserved with DMSO alone and the group cryopreserved with DMSO and albumin (Figs. 2, 3, 4, 5, 6).

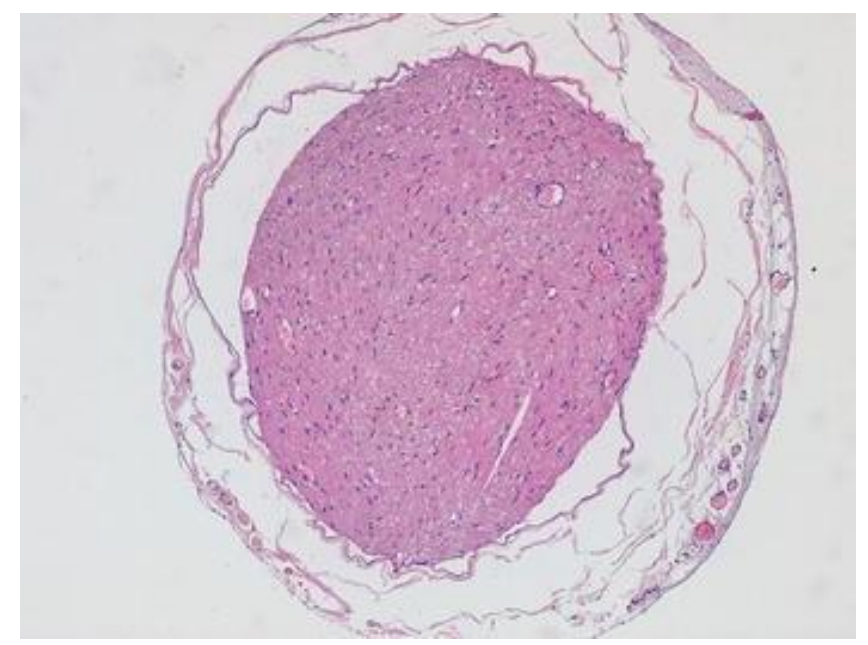

Fig. 2. Hematoxylin and eosin. $\times 10$. Cross section of a normal sciatic nerve

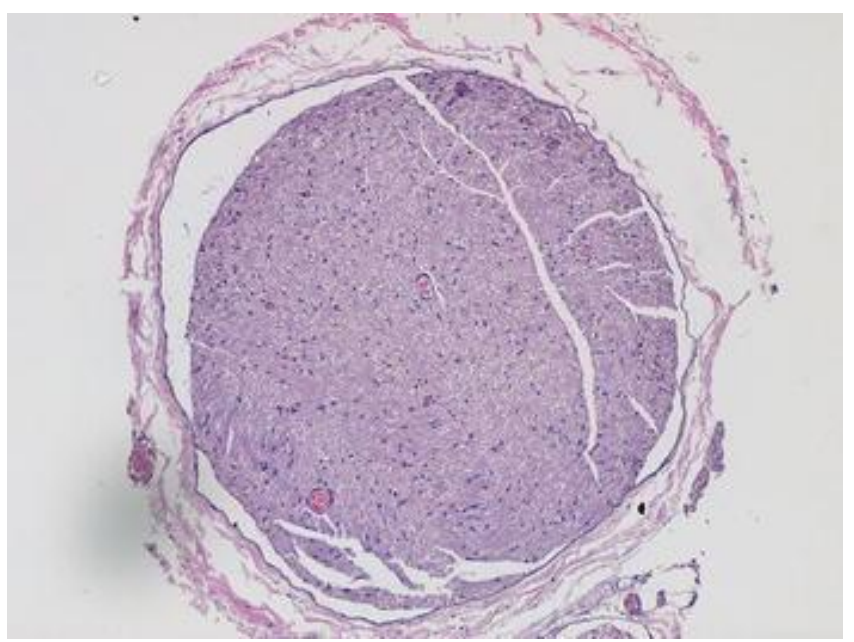

Fig. 3. Hematoxylin and eosin. $\times 10$. Cross section of the sciatic nerve after cryopreservation using DSMO 


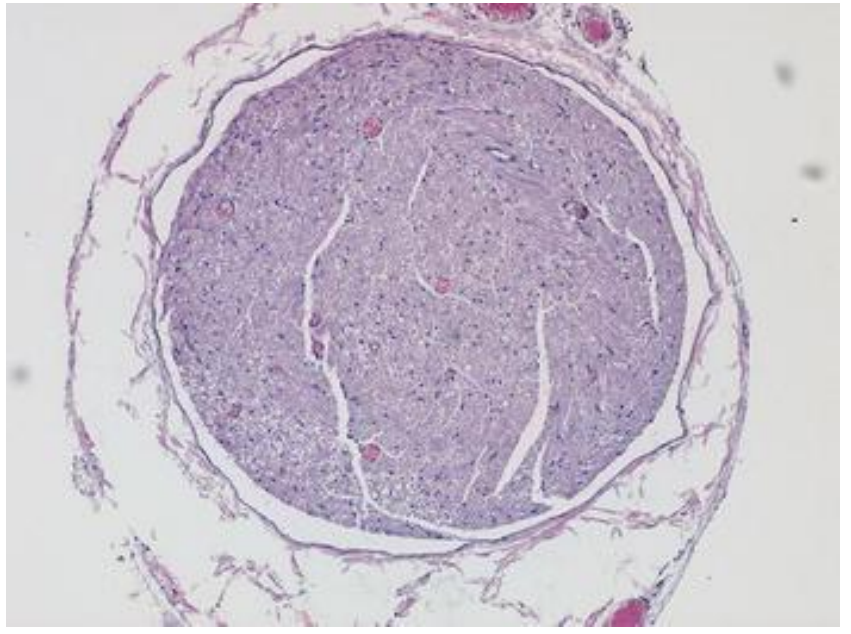

Fig. 4. Hematoxylin and eosin. $\times 10$. Cross section of the sciatic nerve after cryopreservation using DSMO and albumin

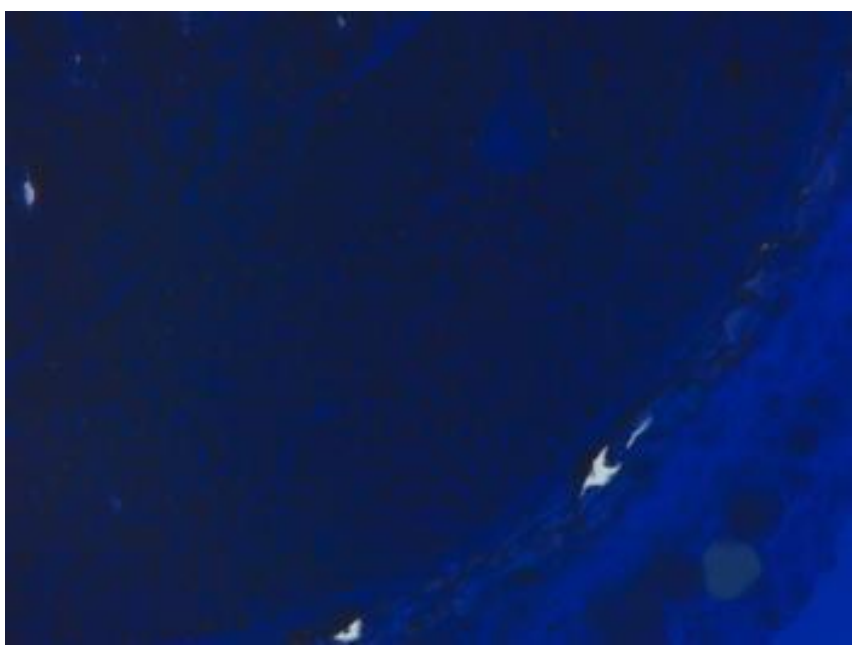

Fig. 5. Toluidine blue. $\times 40$. Cross section of the sciatic nerve after cryopreservation using DMSO 


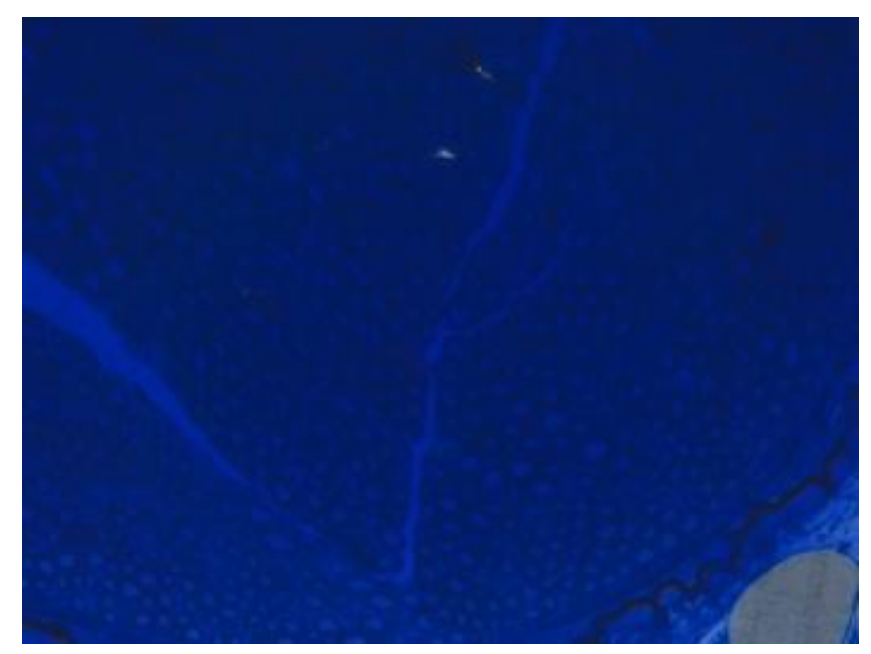

Fig. 6. Toluidine blue. $\times 40$. Cross section of the sciatic nerve after cryopreservation using DMSO and albumin

No morphological alterations in nuclei, epineurium and neural vessels were observed.

\section{Electronic microscopy}

Electronic microscopy of both groups showed intact myelin sheath and basal lamina (Figs. 7, 8, 9). No myelin fragmentation was observed in neither group. Schwann cells structure appeared to be intact. 

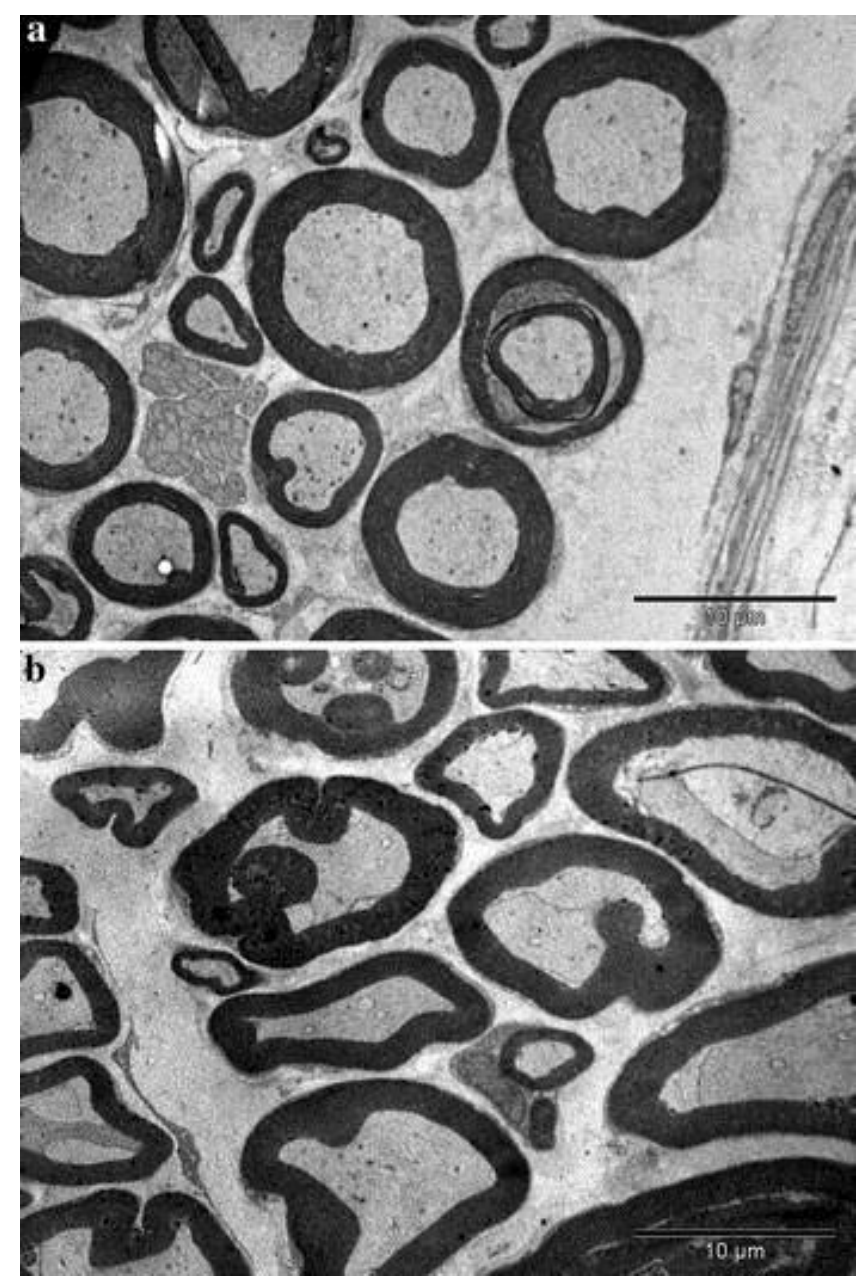

Fig. 7 Electronic microscopy. $\times 3000$. Cross section of a normal sciatic nerve

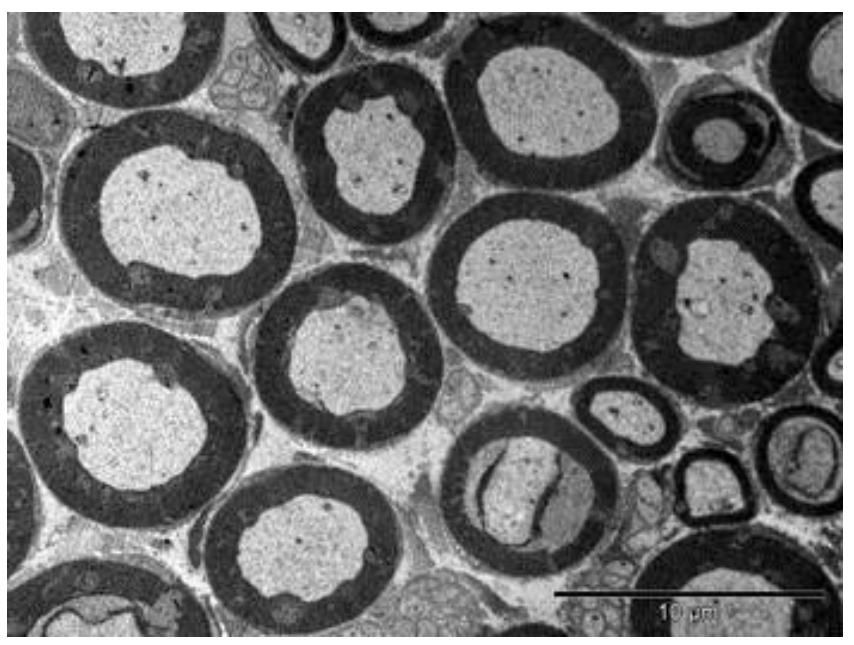

Fig. 8. Electronic microscopy. $\times 4000$. Cross section of the sciatic nerve after cryopreservation using DMSO 

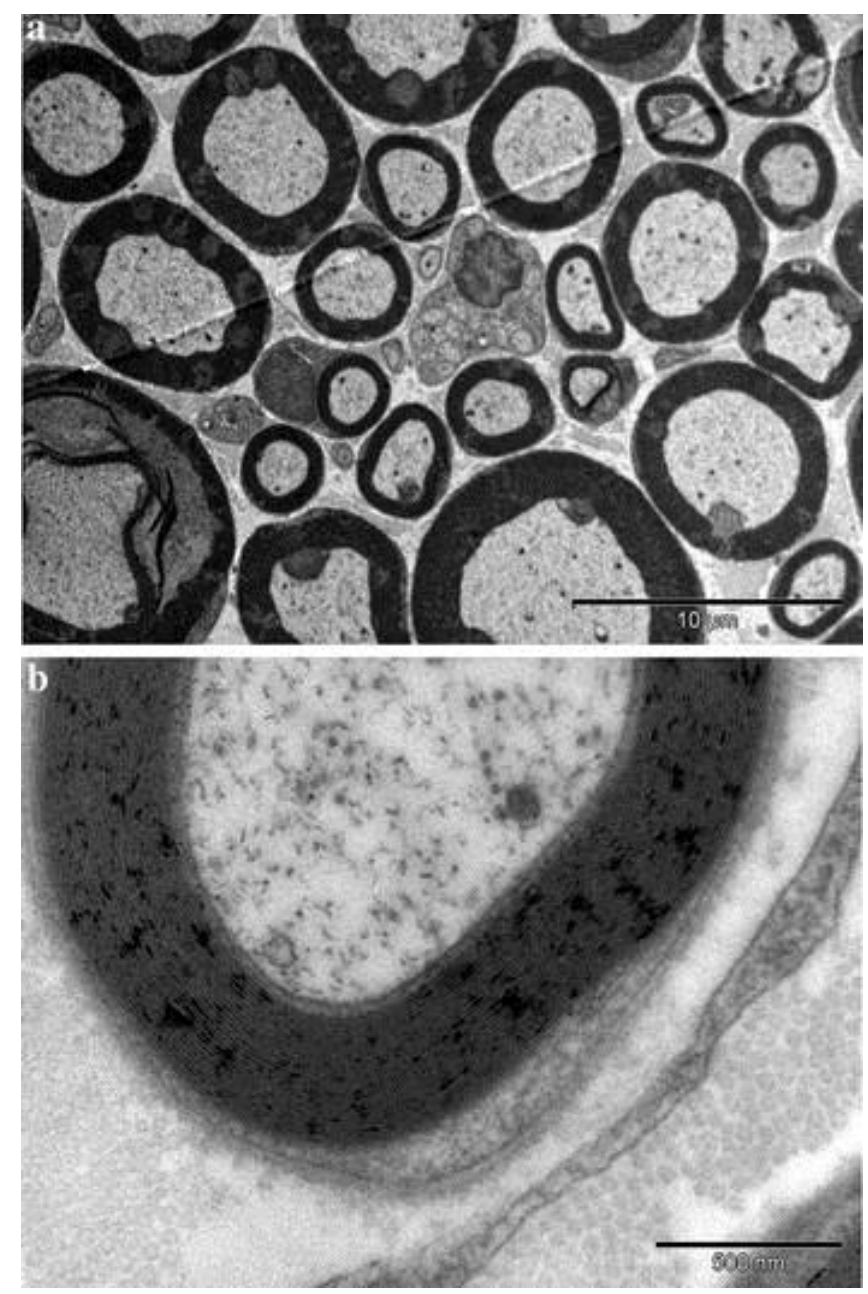

Fig. 9. Electronic microscopy. a shows a cross section of the sciatic nerve $(\times 4000)$ after cryopreservation using DMSO and albumin. b shows the well preserved myelin sheath $(\times 60000)$

\section{CAM and DAPI staining}

The fluorescent intensities of CAM and DAPI staining were measured and compared. The viability, defined as the percentage of fluorescence regarding the fluorescence of the fresh nerve, was significantly higher in DMSO and albumin group (74.9\%, with a standard deviation of $8.1 \%$ ) than that in DMSO group $(61.9 \%$, with a standard deviation of 3.3\%) $(p=0.01)$ (Figs. 10, 11, 12). 

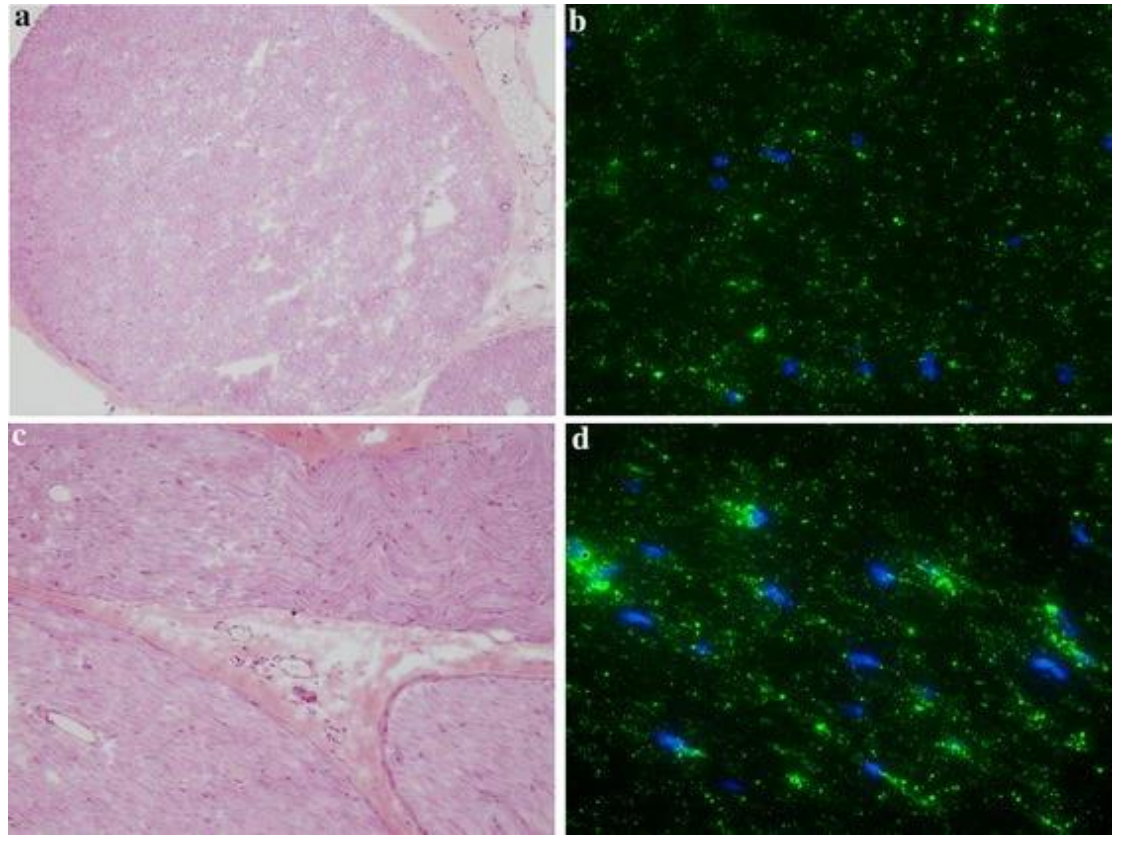

Fig. 10. a A cross section of the fresh sciatic nerve (Hematoxylin and eosin. $\times 20$ ). b The same cross section of the fresh sciatic nerve after CAM and DAPI staining $(\times 40)$. c A longitudinal section of the fresh sciatic nerve (Hematoxylin and eosin. $\times 20$ ), and $\mathbf{d}$ reveals the same longitudinal section of the fresh sciatic nerve after CAM and DAPI staining $(\times 40)$
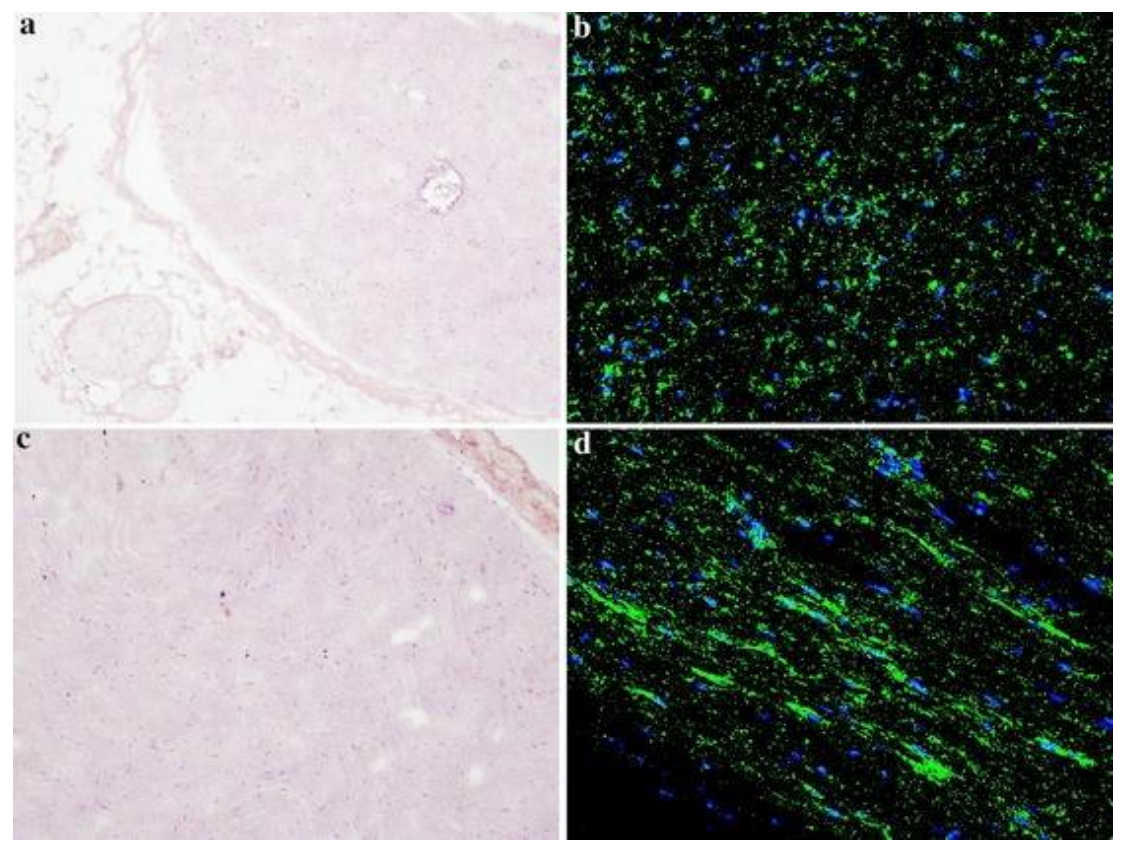

Fig. 11. a A cross section of sciatic nerve after cryopreservation with DMSO (Hematoxylin and eosin. $\times 20$ ). $\mathbf{b}$ The same cross section of the DMSO cryopreserved sciatic nerve after CAM and DAPI staining $(\times 20)$. c A longitudinal section of the cryopreserved sciatic nerve with DMSO (Hematoxylin and eosin. $\times 20$ ), and $\mathbf{d}$ reveals the same longitudinal section of the DMSO cryopreserved sciatic nerve after CAM and DAPI staining $(\times 20)$ 

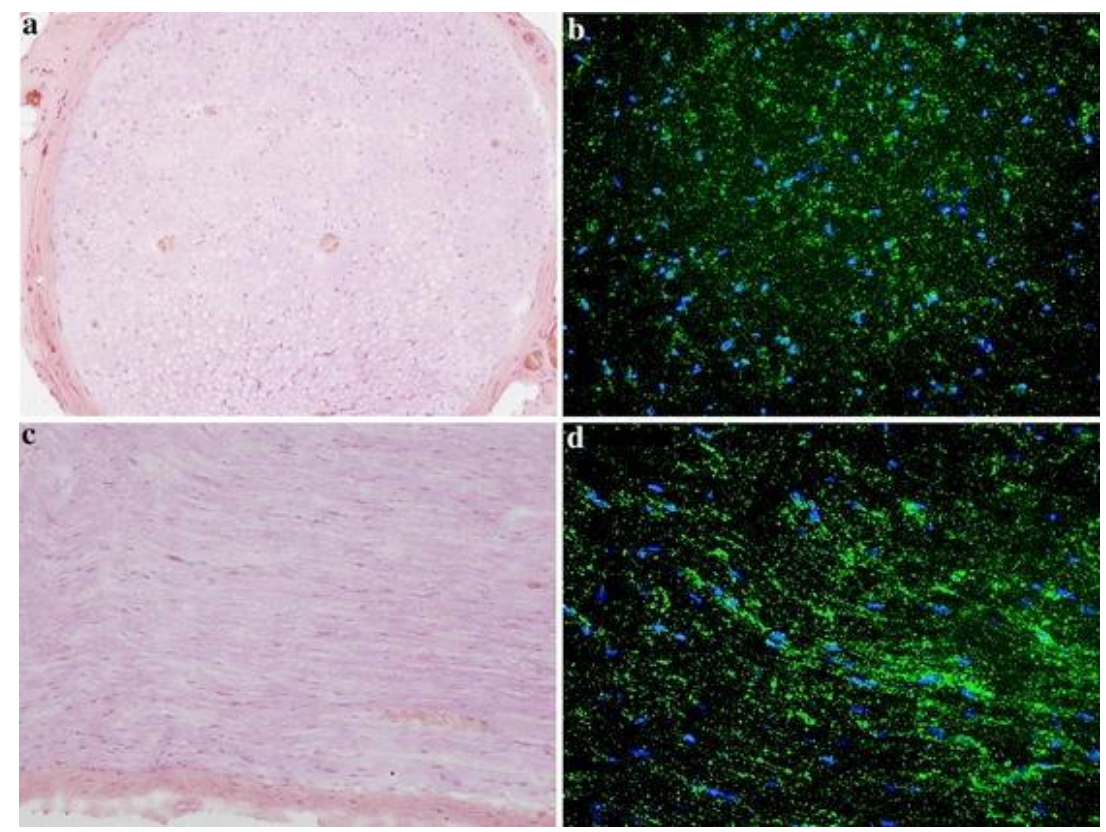

Fig. 12. a A cross section of sciatic nerve after cryopreservation with DMSO and albumin (Hematoxylin and eosin. $\times 20$ ). b The same cross section of the DMSO cryopreserved sciatic nerve after CAM and DAPI staining $(\times 20)$. c A longitudinal section of the cryopreserved sciatic nerve with DMSO (Hematoxylin and eosin. $\times 20$ ), and $\mathbf{d}$ reveals the same longitudinal section of the sciatic nerve after cryopreservation with DMSO and albumin, following CAM and DAPI staining $(\times 20)$

\section{Discussion}

In this study, histological examination of the rat sciatic nerve after cryopreservation demonstrated a proper conservation of nerve structure in both groups, the traditional cryopreservation using DMSO, and the experimental protocol adding albumin. However, Schwann cell viability, assessed by CAM and DAPI staining, was significantly higher in the albumin group.

In the few experimental articles published about nerve cryopreservation, histological structure remains relatively well preserved by either simple freezing or controlled freezing. (Fansa et al. 2000; Zalewski et al. 1993; Zhu et al. 2014b). However, the feature that ultimately determines the efficacy of the cryopreservation protocol is the functionality of the Schwann cells (Fansa et al. 2000).

The cooling rate of the nerve cryopreservation protocols must be low enough to avoid intracellular ice formation, and at the same time fast enough to reduce the cell exposure to the osmotic effect (Fansa et al. 2000).

Slow freezing or low cooling rates have been proposed in the few experimental reports available for nerve cryopreservation (Fansa et al. 2000; Hirasé et al. 1992; Decherchi et al. 1997). In addition, fast thawing is usually the recommended protocol, since its association with higher viability of Schwann cells (Zhu et al. 2014a; Decherchi et al. 1997; Gurina et al. 2016). In this study, we performed a slow freezing protocol of $1{ }^{\circ} \mathrm{C}$ per minute down to $-140{ }^{\circ} \mathrm{C}$, and fast thawing.

As far as cryoprotective agents are concerned, 10\% DMSO has been reported to significantly enhace survival of cultured Schwann cells, but on the other hand it was associated with the inhibition of functional recovery and the generation of cryoinjury in the peripheral nerve (Trumble and Whalen 1992). Nevertheless good results have been published in most experimental studies using DMSO as a cryoprotective agent in the cryopreservation of peripheral nerve (Fansa et al. 2000; Zalewski et al. 1993; Ruwe and Trumble 1990). We did not perform any additional test to make sure the cryoprotectant DMSO was removed after 4 to 5 sequential washings. Despite residual DMSO concentration has been reported to 
be found after thawing in some cryopreserved tissues, this is the general practice of tissue banks when DMSO is used, since the absence of DMSO determined by spectrophotometry was reported after 4 to 5 washings during thawing (Nakamura et al. 2017).

Hirasé et al. used glicerol as a cryoprotective agent, leading to a good axonal regeneration (Hirasé et al. 1992).

Zalewski compared glicerol, DMSO and 2:1 DMSO and formamida, being the glicerol the one with worst results, and DMSO and formamida the best option to preserve Schwann cells (Zalewski et al. 1993). In this study, we used $10 \%$ DMSO as cryoprotective agent.

In terms of the removal of the cryoprotective agent in the thawing phase, the sequential washings seem to be the best method in the nerve vitrification (Decherchi et al. 1997), but there is not enough evidente about the best technique in slow cooling.

Regarding the storage time of the peripheral nerve, it has been reported that long term storaged nerves can lead to excellent axonal regeneration (Hirasé et al. 1992). The storage time in the published protocols for peripheral nerve cryopreservation is about 3 weeks, the same one we chose for this study (Hirasé et al. 1992; Jensen et al. 1990). There are many experimental studies evaluating the viability of Schwann cells when the preservation of the peripheral nerve is at $4{ }^{\circ} \mathrm{C}$, also termed as cold preservation (Lassner et al. 1995; Evans et al. 1995; Evans et al. 1998). However, to the best of our knowledge, there are no studies correlating the Schwann cells viability with the storage time.

The addition of albumin was broadly studied in the cryopreservation protocols for hematopoietic progenitor cells, heart valves, arteries or cornea. Borderie et al. found that the differences in albumin concentration ( $2 \%$ vs. $10 \%$ ) in the cryoprotectant solution had no impact on the number of living cells after cryopreservation of human corneal keratocytes, but failed to evaluate the same protocol of corneal cryopreservation without albumin (Borderie et al. 1998). In our study, just as Decherchi et al. (Decherchi et al. 1997), we added $4 \%$ albumin in the cryoprotectant solution and $20 \%$ albumin in the thawing phase, leading to a significant increase in the viability of Schwann cells, with regard to the use of DMSO without albumin, but we did not evaluate the dosing effect on the viability of Schwann cells. The $4 \%$ albumin in the cryoprotectant solution is the same percentage used for fragile tissues such as ovarian cortex or parathyroid tissue (Krausz et al. 2017). In our preliminary studies, we did a pilot study with 4, 10 and $20 \%$ albumin in the cryoprotectant solution, with the greatest viability being found on the $4 \%$. However, largest groups are needed to reach significant conclusions. We did not test different doses in the thawing phase. As far as we know, there are no studies published evaluating the dose-dependence effect of the addition of albumin in the peripheral nerve cryopreservation protocol.

Several limitations of this study should be considered, such as the low number of samples or the absence of an experimental design that could allow differentiating if the observed effect is due to the presence of albumin in the cryoprotective solution or in the washing solution, or in both of them. In addition, as we already noticed, we did not assess the albumin dosing-dependency of the results, which would require further studies with several subgroups.

In conclusion, despite further studies need to be performed to assess the regeneration through cryopreserved nerve allografts in an in vivo model, we observed that the addition of albumin to the cryopreservation process of peripheral nerves allows a good preservation of the nerve morphology and an increased Schwann cell viability. 


\section{Acknowledgements}

We would like to thank Alberto Centeno for his assistance and commitment in the excellent care taken of the animals, Catalina Sueiro and Ada Castro for their major support in the assessment of the electronic microscopy images, and Jorge Pombo Otero and Ana Reguero for their invaluable assistance in the interpretation of the histological images.

\section{Conflict of interest}

The authors declare that they have no competing interests.

\section{References}

Arav A, Friedman O, Natan Y, Gur E, Shani N (2017) Rat hindlimb cryopreservation and transplantation: a step toward « organ banking». Am J Transplant Off J Am Soc Transplant Am Soc Transpl Surg 17(11):2820-2828

Arnaud F (1992) Future in cryopreservation. Int J Artif Organs 15(11):637-640

Bakhach J, Casoli V, Guimberteau J-C (2007) The cryopreservation of composite tissues: principle, literature review and preliminary results of our own experiments. Ann Chir Plast Esthét 52(5):531-547

Borderie VM, Lopez M, Lombet A, Carvajal-Gonzalez S, Cywiner C, Laroche L (1998) Cryopreservation and culture of human corneal keratocytes. Investig Ophthalmol Vis Sci 39(8):1511-1519

Cui X, Gao DY, Fink BF, Vasconez HC, Rinker B (2007) Cryopreservation of composite tissues and transplantation: preliminary studies. Cryobiology 55(3):295-304

Decherchi P, Lammari-Barreault N, Cochard P, Carin M, Réga P, Pio J et al (1997) CNS axonal regeneration with peripheral nerve grafts cryopreserved by vitrification: cytological and functional aspects. Cryobiology 34(3):214-239

Delbosc B, Herve P, Carbillet JP, Montard M (1984) Corneal cryopreservation in man: a proposal for an original technic. J Fr Ophtalmol 7(4):321-331

Díaz Rodríguez R, Van Hoeck B, De Gelas S, Blancke F, Ngakam R, Bogaerts K et al (2017) Determination of residual dimethylsulfoxide in cryopreserved cardiovascular allografts. Cell Tissue Bank 18(2):263270

Dubernard J-M, Devauchelle B (2008) Face transplantation. Lancet 372(9639):603-604

Evans PJ, Mackinnon SE, Best TJ, Wade JA, Awerbuck DC, Makino AP et al (1995) Regeneration across preserved peripheral nerve grafts. Muscle Nerve 18(10):1128-1138

Evans PJ, Mackinnon SE, Levi AD, Wade JA, Hunter DA, Nakao Y et al (1998) Cold preserved nerve allografts: changes in basement membrane, viability, immunogenicity, and regeneration. Muscle Nerve 21(11):1507-1522

Fairbairn NG, Ng-Glazier J, Meppelink AM, Randolph MA, Valerio IL, Fleming ME et al (2016) Lightactivated sealing of acellular nerve allografts following nerve gap injury. J Reconstr Microsurg 32(6):421-430

Fansa H, Lassner F, Kook PH, Keilhoff G, Schneider W (2000) Cryopreservation of peripheral nerve grafts. Muscle Nerve 23(8):1227-1233

Giwa S, Lewis JK, Alvarez L, Langer R, Roth AE, Church GM et al (2017) The promise of organ and tissue preservation to transform medicine. Nat Biotechnol 35(6):530-542

Grogan SP, Aklin B, Frenz M, Brunner T, Schaffner T, Mainil-Varlet P (2002) In vitro model for the study of necrosis and apoptosis in native cartilage. J Pathol 198(1):5-13

Gurina TM, Pakhomov AV, Polyakova AL, Legach EI, Bozhok GA (2016) The development of the cell cryopreservation protocol with controlled rate thawing. Cell Tissue Bank 17(2):303-316

Hirasé Y, Kojima T, Uchida M, Takeishi M (1992) Cryopreserved allogeneic vessel and nerve grafts: hindlimb replantation model in the rat. J Reconstr Microsurg 8(6):437-443 discussion 445-446

Jensen S, Wallace MN, Dahlerup B (1990) Cryopreservation of rat peripheral nerve segments later used for transplantation. Neuroreport 1(3-4):243-246

Jung H, Kim N, Yoon M (2016) Reproductive stage-dependent effects of additional cryoprotectant agents for the cryopreservation of stallion germ cells. Anim Reprod Sci 173:24-28

Kiroshka V, Trutaieva I, Bondarenko T (2017) Efficiency of mannitol-supplemented medium during adding/removing ovarian tissue with penetrating cryoprotective agents. Cell Tissue Bank 19(1):123132

Krausz MM, Ashkenazi I, Alfici R (2017) Parathyroid autotransplantation in adults and children. Harefuah 156(3):167-170 
Lassner F, Becker M, Fansa H, Walter GF, Berger A (1995) Preservation of peripheral nerve grafts: a comparison of normal saline, HTK organ preservation solution, and DMEM Schwann cell culture medium. J Reconstr Microsurg 11(6):447-453

Li H, Cao H, Guo X, Wang H (2017) Cryovial monolayer vitrification for ovarian tissue cryopreservation. Cell Tissue Bank 19(1):149-154

Lisy M, Kalender G, Schenke-Layland K, Brockbank KGM, Biermann A, Stock UA (2017) Allograft heart valves: current aspects and future applications. Biopreserv Biobank 15(2):148-157

Ma Y-S, Weng S-W, Lin M-W, Lu C-C, Chiang J-H, Yang J-S et al (2012) Antitumor effects of emodin on LS1034 human colon cancer cells in vitro and in vivo: roles of apoptotic cell death and LS1034 tumor xenografts model. Food Chem Toxicol Int J Publ Br Ind Biol Res Assoc 50(5):1271-1278

Mackinnon SE (1989) New directions in peripheral nerve surgery. Ann Plast Surg 22(3):257-273

Martinez-Madrid B, Dolmans M-M, Langendonckt AV, Defrère S, Van Eyck A-S, Donnez J (2004) Ficoll density gradient method for recovery of isolated human ovarian primordial follicles. Fertil Steril 82(6): $1648-1653$

Nakamura Y, Obata R, Okuyama N, Aono N, Hashimoto T, Kyono K (2017) Residual ethylene glycol and dimethyl sulphoxide concentration in human ovarian tissue during warming/thawing steps following cryopreservation. Reprod Biomed Online 35(3):311-313

Pianigiani E, Tognetti L, Ierardi F, Mariotti G, Rubegni P, Cevenini G et al (2016) Assessment of cryopreserved donor skin viability: the experience of the regional tissue bank of Siena. Cell Tissue Bank 17(2):241-253

Rendal Vázquez ME, Rodríguez Cabarcos M, Fernández Mallo RO, Sánchez Ibáñez J, Segura Iglesias R, Bermúdez González T et al (2004) Functional assessment of human femoral arteries after cryopreservation. Cryobiology 49(1):83-89

Routledge C, Armitage WJ (2003) Cryopreservation of cornea: a low cooling rate improves functional survival of endothelium after freezing and thawing. Cryobiology 46(3):277-283

Ruwe PA, Trumble TE (1990) A functional evaluation of cryopreserved peripheral nerve autografts. J Reconstr Microsurg 6(3):239-244

Schneider M, Stamm C, Brockbank KGM, Stock UA, Seifert M (2017) The choice of cryopreservation method affects immune compatibility of human cardiovascular matrices. Sci Rep 7(1):17027

Shabani Nashtaei M, Nekoonam S, Naji M, Bakhshalizadeh S, Amidi F (2017) Cryoprotective effect of resveratrol on DNA damage and crucial human sperm messenger RNAs, possibly through 5' AMPactivated protein kinase activation. Cell Tissue Bank 19(1):87-95

Sriuttha W, Uttamo N, Kongkaew A, Settakorn J, Rattanasalee S, Kongtawelert P et al (2016) Ex vivo and in vivo characterization of cold preserved cartilage for cell transplantation. Cell Tissue Bank 17(4):721734

Trumble TE, Whalen JT (1992) The effects of cryosurgery and cryoprotectants on peripheral nerve function. J Reconstr Microsurg 8(1):53-58 discussion 59-60

Yang I-H, Shin J-A, Lee K-E, Kim J, Cho N-P, Cho S-D (2017) Oridonin induces apoptosis in human oral cancer cells via phosphorylation of histone H2AX. Eur J Oral Sci 125(6):438-443

Zalewski AA, Fahy GM, Azzam NA, Azzam RN (1993) The fate of cryopreserved nerve isografts and allografts in normal and immunosuppressed rats. J Comp Neurol 331(1):134-147

Zhang F, Attkiss KJ, Walker M, Buncke HJ (1998) Effect of cryopreservation on survival of composite tissue grafts. J Reconstr Microsurg 14(8):559-564

Zhu Z, Qiao L, Zhao Y, Zhang S (2014a) Optimal freezing and thawing for the survival of peripheral nerves in severed rabbit limbs. Int J Clin Exp Pathol 7(11):7801-7805

Zhu Z, Qiao L, Zhao Y, Zhang S (2014b) Optimal freezing and thawing for the survival of peripheral nerves in severed rabbit limbs. Int J Clin Exp Pathol 7(11):7801-7805 